\title{
Correlates of Lymphedema in Women with Breast Cancer: a Case Control Study in Shiraz, Southern Iran
}

\author{
Behnam Honarvar ${ }^{1}$, Negin Sayar ${ }^{1 *}$, Sedigheh Tahmasebi², Zeinab Zakeri², \\ Asra Talei ${ }^{2}$, Sara Rostami', Sahar Khademi ${ }^{1}$, Amene Sabzi Sarvestani ${ }^{1}$, Eghbal \\ Sekhavati $^{3}$
}

\begin{abstract}
Globally, the burden of breast cancer (BC) continues to increase. BC related lymphedema (BCRL) is currently non curable and as a life time risk it affects at least $25 \%$ of $\mathrm{BC}$ patients. Knowing more about BCRL and appropriate control of its modifiable risk factors can improve quality of life (QOL) of the affected patients. In this case control study to detect factors, 400 women with BCRL (as the case group) and 283 patients with BC without lymphedema (as the control group) that were referred to Shiraz University of Medical Sciences affiliated BC clinic center were assessed. The data were analyzed in SPSS. The mean age of the case group was $52.3 \pm 11.0$ years and of the control group was $50.1 \pm 10.9$ years. In patients with BCRL, 203(50.7\%) had left (Lt) side BC and in non- lymphedema group $151(53.3 \%)$ had Lt side BC. Out of all BCRL patients, 204 (51\%) had lymphedema in all parts of their affected upper extremities, $100(25 \%)$ had swelling in the arm and forearm and $23(5.7 \%)$ had edema in both the upper extremity and trunk. Edema, heaviness, concern about changing body image, pain and paresthesia were the most common signs/ symptoms among patients with BCRL. In BCRL patients, the difference of circumference between the affected upper limb and non-affected limb was $4.4 \pm 2.5 \mathrm{~cm}$ and the difference in volume displacement was $528.7 \pm 374.4$ milliliters. Multiple variable analysis showed that moderate to severe activity (OR; odds ratio $=14,95 \%$ CI :2.6-73.3), invasiveness of $\mathrm{BC}(\mathrm{OR}=13.7,95 \% \mathrm{CI}: 7.3-25.6)$, modified radical mastectomy (OR=4.3, 95\% CI :2.3-7.9), BMI $=>25(\mathrm{OR}=4.2$, $95 \% \mathrm{CI}: 2-8.7)$, radiotherapy ( $\mathrm{OR}=3.9,95 \% \mathrm{CI}: 1.8-8.2)$, past history of limb damage (OR=1.7, 95\% CI :0.9-3.1) and the number of excised lymph nodes ( $\mathrm{OR}=1.06,95 \% \mathrm{CI}: 1.02-1.09)$ were the significant predictors of lymphedema in women with BC. Modifiable risk factors of BCRL such as non-guided moderate to severe physical activity, high BMI and trauma to the limb should be controlled as early as possible in BC patients to prevent development of BCRL and improve QOL of these patients.
\end{abstract}

Keywords: Breast cancer - determinants - lymphedema - QOL

Asian Pac J Cancer Prev, 17, Cancer Control in Western Asia Special Issue, 81-85

\section{Introduction}

Globally, burden of breast cancer (BC) continues to increase. $\mathrm{BC}$ is the second most common cancer among all cancers and the most frequent cancer among women worldwide including 140 of 184 countries and Eastern Mediterranean Region countries (EMRO). It caused 1 in 4 of all cancers in women with 1.7 million new diagnosed patients in 2012. BC is also the fifth cause of death from cancer with 522,000 deaths in 2012 (Naderimagham et al., 2014).

In Iran, with an age-standardized death rate from cancer of 69.8 per 100,000 for females (Lankarani et al.,2013), BC is the most frequent cancer in women, the $1 \mathrm{st}$ cause $(14.2 \%)$ of death due to cancer among women and the 5 th common cause of death in Iranian women while women of 41-50 years of age group are more affected by it (Afsharfard et al., 2013). The age-standardized incidence rate of $\mathrm{BC}$ has increased from 16.2 in 1996-2000 to more than 25-30 per 100,000 in 2001-2006, meanwhile the age of incidence is about 10 years lower than western countries (Sadjadi et al., 2009). The general mortality rate of $\mathrm{BC}$ increased from 0.9 to 4.3 per 100,000 and more invasive form of $\mathrm{BC}$ is seen among younger age groups (Afsharfard et al., 2013).The Standardized mortality ratios (SMRs) for Iranian women with BC at 5-15 year intervals after diagnosis is 6.7- 1.3 (Haghighat et al., 2012). BC patients suffer from many problems, among these, BC related lymphedema (BCRL) as one of the most important sequelae of the treatment of $\mathrm{BC}$ affects at least 1 in 5 women with BC (Michael et al., 2011; Disipio et al., 2013). BCRL continues to challenge

${ }^{1}$ Health Policy Research Center, ${ }^{2}$ Lymphedema Clinic, Breast Diseases Research Center, Shiraz University of Medical Sciences, Shiraz, ${ }^{3}$ Larestan School of Medical Sciences, Larestan, Iran. *For correspondence: sayar.negin@gmail.com 
clinicians worldwide and it has remained a potentially life-time and irreversible complication that is leaving chronic physical, psychological and emotional consequences for BC patients (Merchant and Chen., 2015). Quality of life (QOL) is impaired remarkably in women with BCRL via inducing pain, heaviness, tightness, decreased range of motion, restriction at work or home, personal care functions and by imposing anxiety, depression, and emotional distress on these patients (Disipio et al., 2013; Taghian et al., 2014; Merchant and Chen., 2015). Some reports showed that lymphedema may also shorten survival (Afsharfard et al., 2013; DiSipio et al., 2013). Therefore, considering increased incidence of $\mathrm{BC}$ and improved 5-year survival of $\mathrm{BC}$ patients, more attention should be focused on QOL of these patients. This study was aimed to improve understanding of correlation between lymphedema in Iranian women with BC to provide more evidences for preventive strategies targeting disabling and distressing disorder.

\section{Materials and Methods}

In this Case Control study, during an 8- month period from February 2014 to September 2015, 400 women with $\mathrm{BC}$ and lymphedema (as the case group) and 283 patients with BC without lymphedema (as the control group) that referred to Shiraz University of Medical Sciences (SUMS) affiliated breast cancer clinic center were assessed. The sample size in the case group was calculated with presumption of $50 \%$ incidence of secondary lymphedema in treated $\mathrm{BC}$ patients, a $5 \%$ precision level, and a confidence level of $95 \%$. Patients were selected through a systematic randomized sampling. Data were extracted from the medical records of patients. Excluded patients were non treated $\mathrm{BC}$ patients, patients with bilateral BC, and patients who were not followed after their treatment. We did not match two groups of case and control, due to presumption of effect of all studied variables in development of lymphedema. Acquired data included demographic characteristics, body mass index (BMI), physical activity (mild, moderate or severe), right versus left side $\mathrm{BC}$, pathologic tumor report (tumor size, being invasive or non-invasive, histological grading), number of lymph nodes that were excised or affected, receptor status of tumor (estrogen, progesterone and human epidermal growth factor receptor (HER2)), presence of metastasis, type of treatment of BC (modified radical mastectomy, conservative surgery, chemotherapy, radiotherapy, hormone therapy), duration and frequency of chemotherapy, radiotherapy, and hormone therapy. Pattern of distribution and signs/ symptoms of lymphedema, past medical history (history of limb damage, lymphangitis, previous lymphedema treatment, diabetes mellitus (DM), hypertension (HTN), congestive heart failure ( $\mathrm{CHF}$ ), family history of lymphedema and treatment for lymphedema (in the case group)) were also acquired. Diagnosis of lymphedema in upper limb was made by measuring the difference of circumference of both upper limbs by the same investigator and with the same procedure. If the circumference differences were 2 centimeters $(\mathrm{cm})$ or higher in any corresponding point, the patient was considered a lymphedema case. Another method of detection of lymphedema of upper extremity was volumetric measurement test through determining water volume displacement and volume reduction by affected limb with lymphedema compared to non- involved limb (McNeely et al.,2004). Volumes were measured in two specially-constructed cylindrical plexi-glass tanks that both have two drainage taps. The main (internal) tank measured $70 \mathrm{~cm}$ in height by $21 \mathrm{~cm}$ in diameter. The external tank measured $60 \mathrm{~cm}$ in height and $31 \mathrm{~cm}$ in diameter. The internal tank has section area about 330 $\mathrm{cm}^{2}$ and was filled with water to a height of $70 \mathrm{~cm}$. The external tank's outer wall was marked in millimeters $(\mathrm{ml})$ and $\mathrm{cm}$ to show the height of the water that over-flowed from the inner tank. While standing next to the device, the patient immersed her straightened healthy arm and hand into the inner tank up to a point $15 \mathrm{~cm}$ above the olecranon. The height of the displaced water and amount of water spilled into the outer tank were measured in centimeters. Then the patient removed her healthy upper limb and immerses the affected arm and hand into the internal tank, and the height of the displaced water was recorded. To calculate the volume of water displaced by the arm with lymphedema compared to the unaffected limb in $\mathrm{ml}$, the difference between the two measurements was multiplied by the section area of the inner tank $(330 \mathrm{~cm})$ (Mcneely et al.,2004). Moreover, Stemmer's test results were collected. To perform this test, skinfold at the base of the second toe or middle finger should be pinched and lifted. Failure to pinching and lifting the skin means that Stemmer's sign is positive and is the sign of lymphedema (Iuchi et al.,2015).

All data were analyzed in the SPSS version 20 software (SPSS, Chicago, IL, USA). The accuracy of data entry was ensured by randomly selecting and checking data against their corresponding data in the SPSS software. Chi squared and t tests were used as appropriate. After single variable analysis, multiple analysis was done by including variables with $\mathrm{p}$ values $<0.2$ in the logistic regression (Enter method). $\mathrm{P}$ values less than 0.05 was considered significant.

\section{Ethics}

The protocol of this research was approved by research ethics committee of health policy research center affiliated with SUMS.

\section{Results}

Out of 683 studied women with BC, 400(58.6\%) had BCRL compared to 283(41.4\%) who had only BC. The mean age of case group was $52.3 \pm 11$ years compared to the control group that was $50.1 \pm 10.9$ years $(\mathrm{P}=0.01)$ (Table 1). In patients with lymphedema, 203(50.7\%) had left (Lt) side BC and in non-lymphedema group $151(53.3 \%)$ had Lt side BC ( $\mathrm{P}=0.5)$. In BCRL patients 204 $(51 \%)$ had lymphedema in all parts of the affected upper extremity, 100(25\%) had swelling in the arm and forearm and $23(5.7 \%)$ had edema in both upper extremity and trunk, while the rest had a different pattern of distribution 
DOI:http://dx.doi.org/10.7314/APJCP.2016.17.S3.81 Correlates of Lymphedema in Women with Breast Cancer: a Case Control Study in Shiraz, Southern Iran

Table 1 . Single Variable Analysis in Patients with Breast Cancer and Lymphedema (Case Group, n=400) Compared to Patients with Breast Cancer without Lymphedema (Control Group, n=283) (Mild: Sitting, Standing Still or Lying Down, Moderate:Routine Walking, House Working or any Other Activity More than Mildly but to Highly Demanding, High: Aerobic Exercise, Hard House Working, Climbing Stairs or any Other Activity Causing Sweating or Increased Heart Rate.

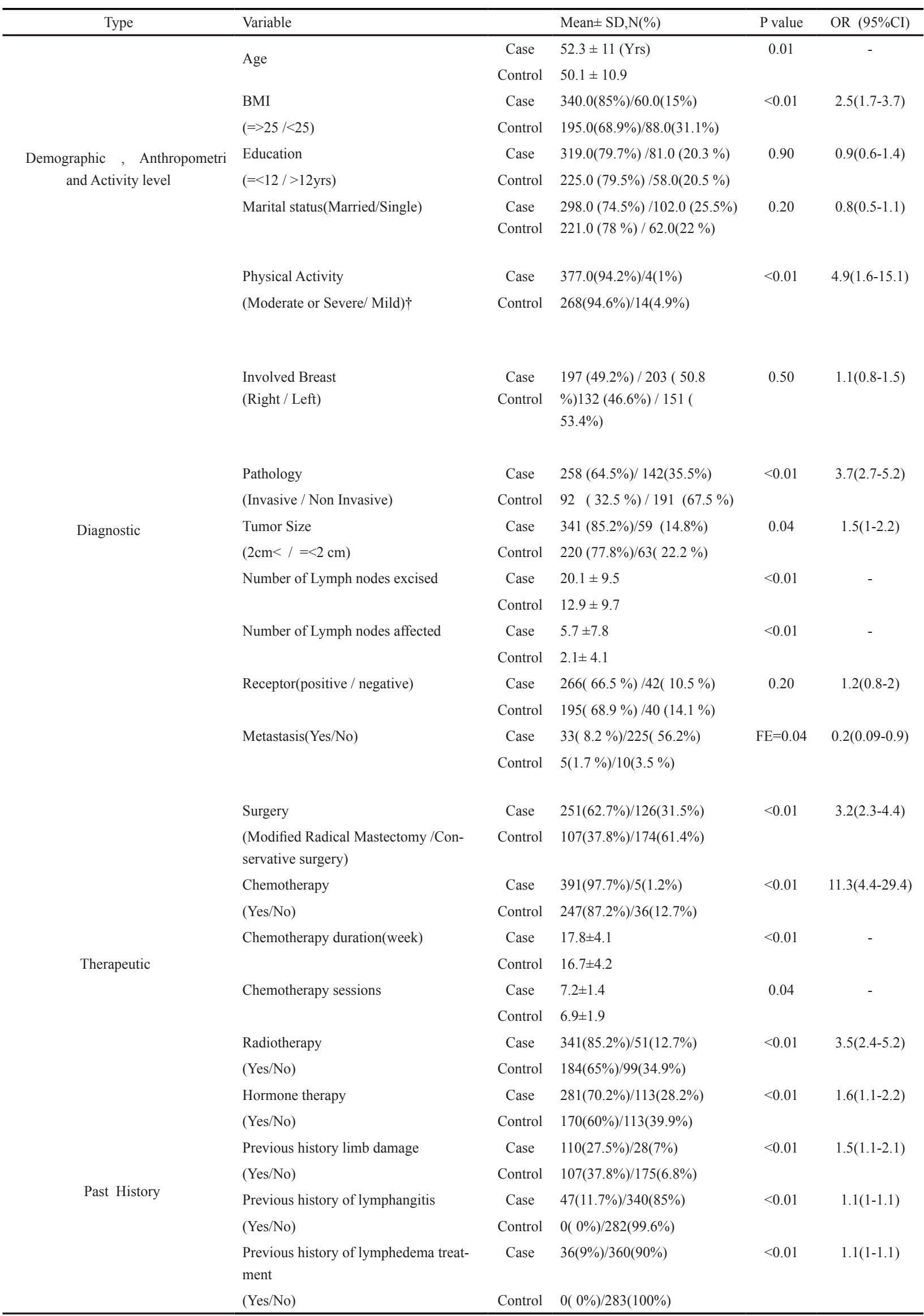


of lymphedema. Moreover, in the case group 185 (46.2\%) had concern about their body image. In BCRL patients, the difference of circumference between affected upper limb and non-affected limb was $4.4 \pm 2.5 \mathrm{~cm}$ and the difference in volume displacement by volumetric measurement test was $528.7 \pm 374.4 \mathrm{ml}$. Most of patients with BCRL (258; $64.5 \%$ ) had invasive BC compared to the majority of non-lymphedema group $(191 ; 67.4 \%)$ that had non-invasive types of $\mathrm{BC}(\mathrm{P}<0.01)$. Similarly, chemotherapy was 11.3 times, moderate to severe physical activity was 4.9 times, radiotherapy was 3.5 times, modified radical mastectomy was 3.2 times, BMI was 2.5 times, hormone therapy was 1.6 times, tumor size larger than $2 \mathrm{~cm}$ was 1.5 times and number of excised or affected lymph nodes were more frequent in the lymphedema group $(\mathrm{P}<0.05)$ (Table1).Moreover, edema was 36.4 times, paresthesia was 5.6 times, sense of heaviness was 5.5 times, moderate to severe pain was 4.7 times, lymphostasis was 3 times, Stemmer's sign was 2.8 times, previous history of upper limb damage was 1.5 times, limited range of motion of upper extremity was 1.3 times and history of lymphangitis was 1.1 times more common in BCRL group. However, education, having job, marital status, frequency of right (Rt) versus Lt hand dominancy, histological grading of $\mathrm{BC}$, existing receptors in involved tissues, Rt vs. Lt mastectomy, comorbidities, markers of cancers (CA 15-3,CA 125, CEA; carcino embryogenic antigen) were not different among $\mathrm{BC}$ patients with or without lymphedema $(\mathrm{P}>0.05)$. Multiple variable analysis showed that moderate to severe activity $(\mathrm{OR}$; odds ratio $=14)$, invasiveness of tumor $(\mathrm{OR}$ $=13.7)$, modified radical mastectomy $(\mathrm{OR}=4.3)$, $\mathrm{BMI}$ $\Rightarrow 25(\mathrm{OR}=4.2)$, radiotherapy $(\mathrm{OR}=3.9)$, past history of limb damage $(\mathrm{OR}=1.7)$ and the number of excised lymph nodes $(\mathrm{OR}=1.1)$ were significant predictors of

Table 2. Multiple Variable Analysis (Logistic Regression: Enter Method) in Patients with Breast Cancer and Lymphedema

\begin{tabular}{|c|c|c|c|}
\hline Variable & OR & CI 95\% & $P$ value \\
\hline $\begin{array}{l}\text { Physical Activity } \\
\text { (Moderate-Severe, Mild) }\end{array}$ & 14.0 & $2.6-73.3$ & $<0.01$ \\
\hline $\begin{array}{l}\text { Pathology } \\
\text { (Invasive, Non Invasive) }\end{array}$ & 13.7 & $7.3-25.6$ & $<0.01$ \\
\hline $\begin{array}{l}\text { Surgery } \\
\quad \text { (Modified Radical } \\
\text { Mastectomy, Conservative } \\
\text { Surgery) }\end{array}$ & 4.3 & $2.3-7.9$ & $<0.01$ \\
\hline $\begin{array}{l}\text { BMI } \\
\qquad(>=25,<25)\end{array}$ & 4.2 & $2-8.7$ & $<0.01$ \\
\hline $\begin{array}{c}\text { Radiotherapy } \\
\text { ( Yes, No) }\end{array}$ & 3.9 & $1.8-8.2$ & $<0.01$ \\
\hline $\begin{array}{l}\text { History of Limb damage } \\
\text { (Yes, No) }\end{array}$ & 1.7 & $0.9-3.1$ & 0.05 \\
\hline $\begin{array}{l}\text { Number of Lymph nodes } \\
\text { excised }\end{array}$ & 1.1 & $1-1.1$ & $<0.01$ \\
\hline
\end{tabular}

lymphedema in women with BCRL (Table 2).

\section{Discussion}

$\mathrm{BC}$ has an increasing trend and involves the younger ages more than before. On the other hand, mortality among $\mathrm{BC}$ patients is decreasing, however, there are many issues such as BCRL, changed body image, depression, anxiety, stress, changes in relationships with husband and children, dealing with any ongoing side effects and the fear of BC recurrence that these women are chronically challenging (Fu MR., 2014; Jassim et al.,2015). Among these problems, BCRL develops within three years of a BC diagnosis but can occur much later (Fu.,2014). BCRL affects more than one in five women and is currently non curable (Disipio et al., 2013; Iuchi et al.,2015). BCRL imposes physical, psychological and heavy cost consequences upon BC patients (Alcorso and Sherman.,2015; Fu., 2014). Our study revealed that edema, heaviness, concern about body image, pain and paresthesia are the most common signs/symptoms among patients with BCRL. These may be the earliest alarming signs of BCRL as was noted by another study and therefore physicians should be educated about them. (Fu MR., 2014). However, knowing about risk factors of BCRL is more important and may help its prevention. Different studies showed a more and less variant picture of BCRL related risk factors. One study found that breast surgery (lumpectomy or mastectomy), sentinel lymph node biopsy or dissection of axillary lymph nodes, radiotherapy, or chemotherapy, obesity or weight gain after diagnosis, even minor upper extremity infections, trauma to the affected limb, or overuse of the limb are involved in development of BCRL (Fu MR., 2014). Another survey detected that in addition to axillary lymph node dissection $(\mathrm{OR}=3.7)$, hypertension $(\mathrm{OR}=1.8)$, high body mass index $(\mathrm{OR}=1.8)$, chemotherapy $(\mathrm{OR}=1.3)$ and radiotherapy $(\mathrm{OR}=1.3)$ were effective in BCRL developing ( $\mathrm{Zhu}$ et al., 2014).More radical axillary surgery, more affected axillary nodes, a postoperative axillary hematoma, seroma, infection, and nodal radiation were also found to be related to BCRL (Golshan M and Smith B.,2006). According to other evidence, correlation of the BMI $\geq 30 \mathrm{~kg} / \mathrm{m}^{\wedge} 2$ (OR 1.6),removal of greater number of lymph nodes $(\mathrm{OR}=1.1)$ and longer interval since surgery (OR $=2.3$ at 18 months) were known as correlates of BCRL (Voss et al.,2015).It was shown that overweight BC patients treated with tamoxifen were also at risk of lymphedema and a weight reduction in these patients helps to treat them (Das et al., 2015). On the other hand, T classification $(\mathrm{OR}=0.5)$ and stage $(\mathrm{OR}=0.6)$ were protective against lymphedema, whileage, number of positive lymph nodes, and number of lymph node dissection did not show an obvious correlation (Zhu et al., 2014). In our study, moderate to severe physical activity, invasiveness of BC, modified radical mastectomy, $\mathrm{BMI}=>25$, radiotherapy, past history of limb damage and number of excised lymph nodes were the most significant predictors of lymphedema in women with BCRL respectively. These findings are compatible with other 
studies, except that there are contradictory evidences about the effect of physical activity in development or protection of lymphedema. Several studies recommend a guideline based physical exercise in BCRL patients (Fu MR., 2014; Zhu et al., 2014; Voss et al.,2015) . Moreover, reduction of BMI in obese BC patients, prevention of infection or trauma have a protective role against BCRL (Fu MR., 2014; Voss et al.,2015).

Our limitation in this study was that if we could follow the $\mathrm{BC}$ patients in a prospective manner, the risk of development of $\mathrm{BCRL}$ in relation to the time could also be measured. Moreover, we should not have overlooked the role of well informed physicians that can empower BC patients by presenting or reinforcing risk reduction information to them (Fu MR., 2014). The role of education of people as well as primary care physician to prevent or at least improve the care for BCRL has been proved in another study (Mete Civelek et al.,2015).Therefore, recently launched family physician program in Fars province of Iran should be considered as a golden opportunity to integrate preventive and supportive care of patients with BCRL in this program (Honarvar et al.,2015). Expanding the lymphedema clinics that provide a more specialized diagnostic and therapeutic services for BCRL patients is also needed.

In conclusion, modifiable risk factors of BCRL such as non -guided moderate to severe physical activity, high BMI and trauma to the limb should be controlled as early as possible in $\mathrm{BC}$ patients to improve their QOL.

\section{Acknowledgements}

The authors are grateful to the staff of lymphedema clinic and Breast Diseases Research Center affiliated with SUMS for their sincere cooperation in this project. This manuscript was extracted from the MD thesis (NO. 93-01-01-7701) of Negin Sayar that was approved and granted by vice chancellor of research, SUMS. The authors do not have any conflict of interest to declare.

\section{References}

Afsharfard A, Mozaffar M, Orang E, et al (2013). Trends in epidemiology, clinical and histopathological characteristics of breast cancer in Iran: results of a 17 year study. Asian Pac J Cancer Prev, 14, 6905-11.

Alcorso J, Sherman KA (2015). Factors associated with psychological distress in women with breast cancer-related lymphoedema. Psychooncology, 22, 1466-84.

Das N, Baumgartner RN, Riley EC, et al (2015). Treatment-related risk factors for arm lymphedema among long-term breast cancer survivors. J Cancer Surviv, 9, 422-30.

Disipio T, Rye S, Newman B, et al (2013). Incidence of unilateral arm lymphoedema after breast cancer: a systematic review and meta-analysis. Lancet Oncol, 14, 500-15.

Fu MR (2014). Breast cancer-related lymphedema: Symptoms, diagnosis, risk reduction, and management. World J Clin Oncol, 5, 241-7.

Golshan M, Smith B (2006). Prevention and management of arm lymphedema in the patient with breast cancer. $J$ Support Oncol, 4, 381-6.

Haghighat S, Akbari ME, Ghaffari S, et al (2012). Standardized breast cancer mortality rate compared to the general female population of Iran. Asian Pac J Cancer Prev, 13, 5525-8.

Honarvar B, Lankarani KB, Rostami S, et al (2015). Knowledge and practice of people toward their rights in urban family physician program: a population-based study in Shiraz, Southern Iran. Int J Prev Med, 4, 46.

Iuchi T, Dai M, Sanada H, et al (2015).Associations between the treatments and outcomes of patients with upper and lower lymphoedema in Japan: a cross-sectional observational study. Int J Nurs Stud, 52, 913-9.

Jassim GA, Whitford D1, Hickey A,Carter B, et al (2015). Psychological interventions for women with non-metastatic breast cancer. Cochrane Database Syst Rev, 28, 5.

Lankarani KB, Khosravizadegan Z, Rezaianzadeh A, Honarvar B, et al (2013). Data coverage of a cancer registry in southern Iran before and after implementation of a population-based reporting system: a 10-year trend study. BMC Health Serv Res, 6, 169.

McNeely ML, Magee DJ, Lees AW, Bagnall KM, et al (2004). The addition of manual lymph drainage to compression therapy for breast cancer related lymphedema: a randomized controlled trial. Breast Cancer Res Treat, 86, 95-106.

Merchant SJ, Chen SL (2015). Prevention and management of lymphedema after breast cancer treatment. Breast J, 21, 276-84.

Mete Civelek G, Aypak C, Turedi O (2015). Knowledge of primary care physicians about breast-cancer-related lymphedema: Turkish perspective. J Cancer Educ, 4, 217-20.

Michael S, Charikleia S, Konstantinos K (2011). Lymphedema and breast cancer: A review of the literature. Br J Cancer, 18, 174-80.

Naderimagham S, Alipour S, Djalalinia S, et al (2014). National and sub-national burden of breast cancer in Iran; 1990-2013. Arch Iran Med, 17, 794-9.

Sadjadi A, Nouraie M, Ghorbani A, et al (2009). Epidemiology of breast cancer in the Islamic Republic of Iran: first results from a population-based cancer registry. East. Mediterr. health $j, 15,1426-31$.

Taghian NR, Miller CL, Jammallo LS, et al (2014). Lymphedema following breast cancer treatment and impact on quality of life: a review. Crit Rev Oncol Hematol, 92, 227-34.

Voss RK, Cromwell KD, Chiang YJ, et al (2015). The long-term risk of upper-extremity lymphedema is two-fold higher in breast cancer patients than in melanoma patients. J Surg Oncol, 112, 834-40.

Zhu YQ, Xie YH, Liu FH, et al (2014). Systemic analysis on risk factors for breast cancer related lymphedema. Asian Pac J Cancer Prev, 15, 6535-41. 